
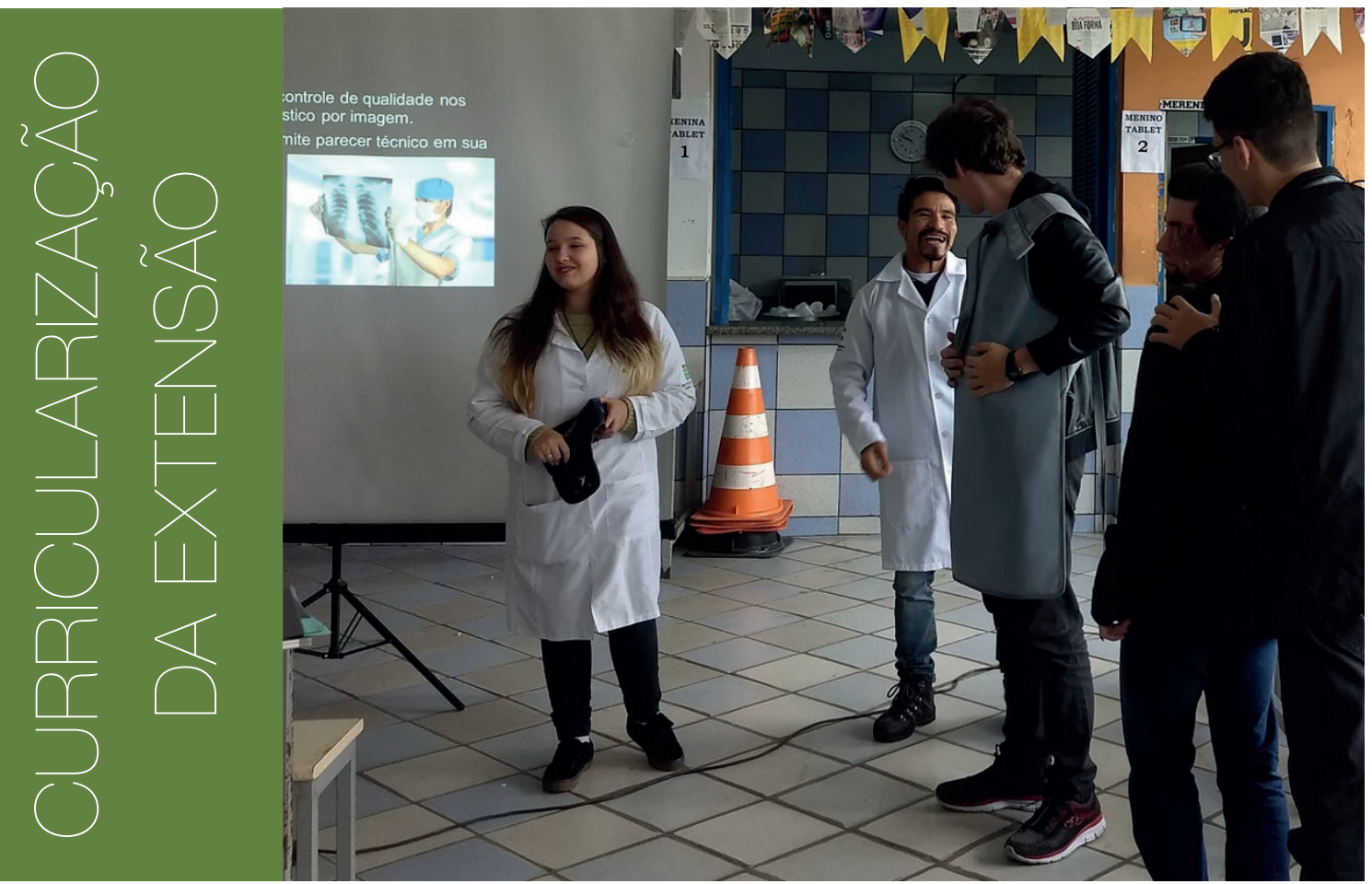

\title{
Curricularização da extensão: uma abordagem na educação básica acerca da radiologia e suas vertentes
}

\author{
Maria Júlia da Silva - mariajuliaasilva27@gmail.com \\ Senédia Menezes de Morais - senedia.mm@gmail.com² \\ Whilliam Guilherme Amaral - willbio10@gmail.com³ \\ Charlene da Silva - tcn.charlene.silva@gmail.com²
}

\section{RESUMO}

0 relato em questão retrata um projeto de extensão no qual os graduandos da terceira fase do curso superior de tecnologia em Radiologia do Câmpus Florianópolis do Instituto Federal de Santa Catarina apresentam a Radiologia e o IFSC para alunos do ensino médio em uma instituição pública. Com base na experiência, conclui-se que a ação da extensão permite a troca de conhecimentos, colaborando na formação acadêmica dos discentes.

\section{PALAVRAS-CHAVE}

Radiologia. Relações Comunidade-Instituição. Comunidade.

1,2, 3 Graduandos do Curso Superior de Tecnologia em Radiologia do Instituto Federal de Santa Catarina, Câmpus Florianópolis.

2 Tecnóloga em Radiologia, Docente do Curso Superior de Tecnologia em Radiologia do Instituto Federal de Santa Catarina, Câmpus Florianópolis. 


\section{ABSTRACT}

The report in question depicts an extension project, where the undergraduates of the third phase of the CST in Radiology have the radiology and the IFSC, for students in the third year of secondary education in a public institution. Based on the experience concludes that the action of the extension allows the exchange of knowledge by collaborating in the education of students.

\section{KEYWORDS}

Radiology. Community-Institutional Relations. Community.

\section{Relato de experiência}

0 Fórum de Pró-Reitores de Extensão das Universidades Públicas Brasileiras (2010) estabeleceu a Política Nacional de Extensão, que define as diretrizes para a extensão, expressas em "impacto e transformação", "interação dialógica", "interdisciplinaridade" "indissociabilidade ensino pesquisa - extensão".

De acordo com Saraiva (2007), a extensão possibilita ao acadêmico a experiência de vivências significativas que the proporciona reflexões acerca das grandes questões da atualidade e, com base na experiência e nos conhecimentos produzidos e acumulados, o desenvolvimento de uma formação compromissada com as necessidades nacionais, regionais e locais, considerando-se a realidade brasileira.

Partindo da relevância da curricularização da extensão, a turma 2017 do Curso Superior de Tecnologia em Radiologia do Instituto Federal de Santa Catarina (IFSC), Câmpus Florianópolis, desempenhou uma atividade de extensão, sendo escolhidas duas turmas de terceiro ano do ensino médio da Escola de Educação Básica Presidente Juscelino Kubitschek.

A atividade teve como função proporcionar o conhecimento acerca do conceito da radiação à comunidade, e, por se tratar de alunos cursando o terceiro ano do ensino médio, o projeto discutiu sobre a atuação do tecnólogo em Radiologia no mercado de trabalho.

A partir da disciplina "Atividade de extensão 1", ministrada pelas professoras Caroline Medeiros e Charlene da Silva, houve a formação do grupo para dar início ao projeto. 0 grupo foi composto, obrigatoriamente, por componentes de ambos os sexos e diferentes faixas etárias, sendo que a atividade a ser desenvolvida e o público de interesse ficou a critério do grupo.

A segunda etapa desenvolvida foi a pesquisa e leitura de artigos científicos relacionados a projetos de extensão e ao tema escolhido. Neste caso, conceitos básicos sobre a radiologia, além de apresentar as áreas de atuação do tecnólogo e suas funções no mercado de trabalho de acordo com sua especificidade.

A etapa seguinte foi a escolha do público, sendo a instituição anteriormente citada, localizada no bairro Areias, no município de São José, Santa Catarina. A escolha do referido público se deu pelo objetivo de apresentar noções básicas sobre radiação, temática presente no conteúdo programático do ensino médio, além de apresentar o IFSC e conhecer o profissional formado tecnólogo em Radiologia para a divulgação da profissão e assim despertar o interesse nos alunos pela área e pela instituição de ensino, no caso, o IFSC.

Posteriormente a equipe definiu a estratégia de apresentação do tema aos alunos. Os conceitos foram abordados a partir de uma apresentação com recurso multimídia (projetor) para um entendimento didático por parte dos alunos. A escolha desta estratégia se deu pelo fato do referido público estar ambientado com este tipo de abordagem pelos professores. Após o término da apresentação, para uma melhor compreensão do assunto, a equipe propôs à turma uma dinâmica com perguntas e respostas sobre o tema, recompensando as respostas corretas.

A quinta etapa foi o contato com a responsável pela instituição de ensino na qual a atividade 
seria realizada, obedecendo todos os trâmites legais e burocráticos, ou seja, envio do pedido por meio de documento fornecido pelo, com a assinatura das professoras orientadoras do projeto e ministrantes da disciplina de extensão para o conhecimento e permissão por parte da gestora da escola.

Uma atividade de extensão pode se desenvolver de diversas formas, e neste caso optou-se por fazer um projeto. Para Menegon (2015), um projeto consiste em ações de caráter educativo, cultural, social, científico e tecnológico, sendo articuladas de forma que se tornem relevantes e de grande valia para a comunidade, além de contribuir para a formação acadêmica do discente, pela agregação de conhecimentos adquiridos nas atividades feitas junto à comunidade.

Neste projeto foram escolhidas duas turmas do terceiro ano do ensino médio como público alvo para a palestra informativa, sendo apresentado o tema "Radiologia e suas vertentes". Na Figura 1 observam-se os alunos da graduação ministrando a palestra.

Figura 1: Apresentação dos discentes. Fonte: Dados deste projeto.

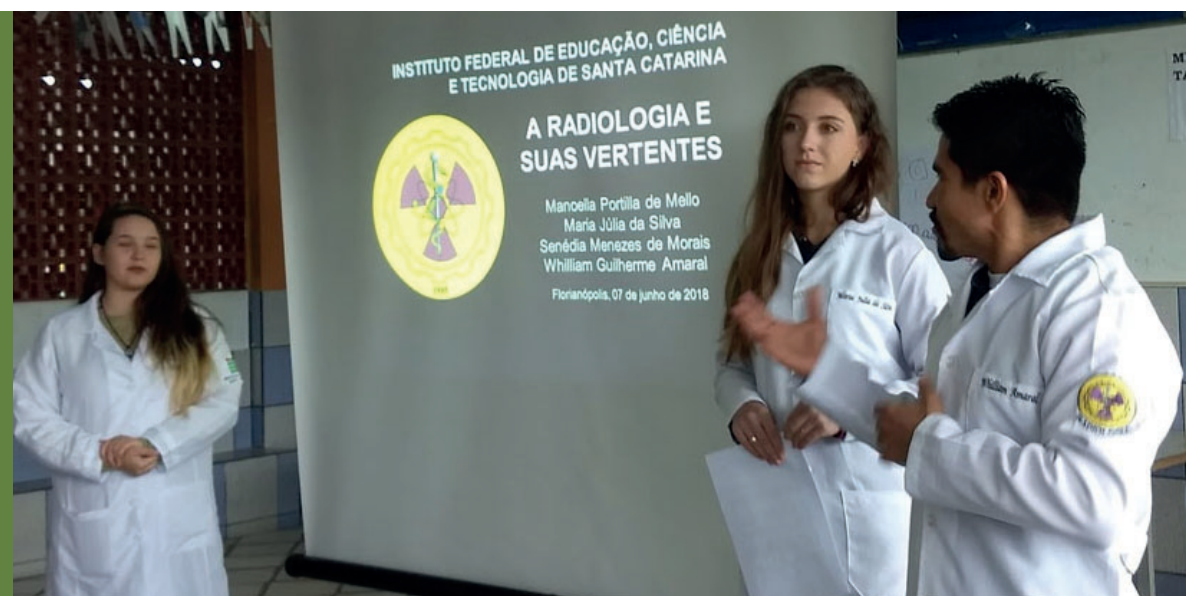

A apresentação contou com a participação continuada dos alunos, como pode ser visto na Figura 2, onde os graduandos puderam interagir com os alunos, sanando dúvidas ao longo do processo educativo.

Figura 2: Interação entre discentes e comunidade. Fonte: Dados deste projeto.

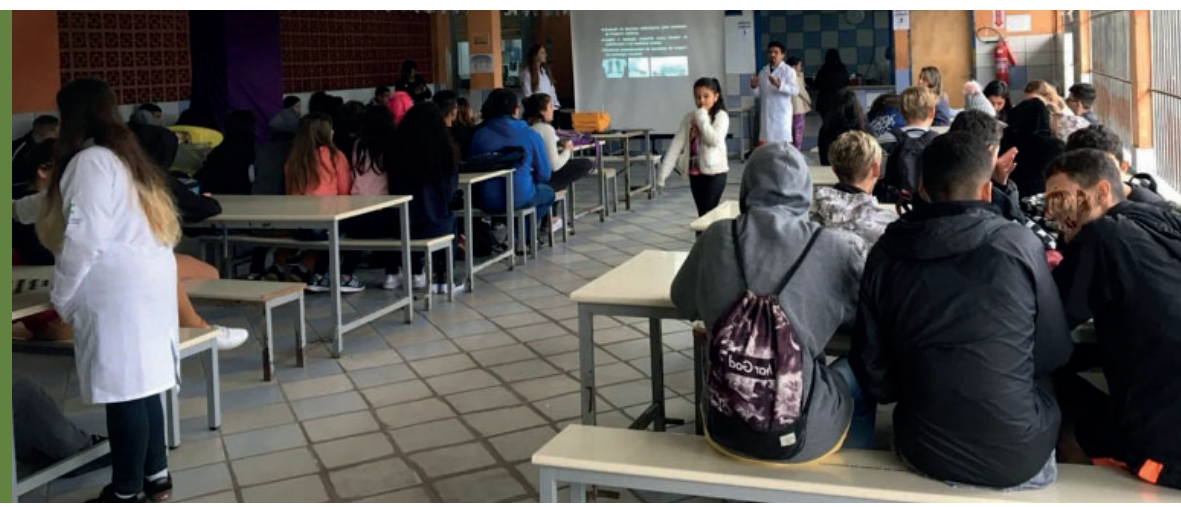

A comunidade foi composta por aproximadamente 60 alunos, todos na faixa dos 16 aos 19 anos. A maioria tem pretensão de fazer o Exame Nacional do Ensino Médio (Enem) e/ou vestibulares para ingressar em algum curso superior, sendo que uma parte significativa tem interesse na área da saúde, tal fato confirmado em um momento da apresentação onde os alunos foram questionados sobre seus anseios.

Os estudantes se mostraram impressionados quando as fontes naturais de radiação ionizantes foram apontadas, levantando questionamentos. Além disso, também foi perceptível o interesse pelas vestimentas de proteção radiológica. Muitos quiseram prová-las.

Como finalização, foi ministrada uma dinâmica que consistia em um questionário com cinco perguntas objetivas com 0 intuito de testar os conhecimentos adquiridos. Os alunos se mostraram interessados em acertar as questões, como pode ser visualizado na Figura 3. 


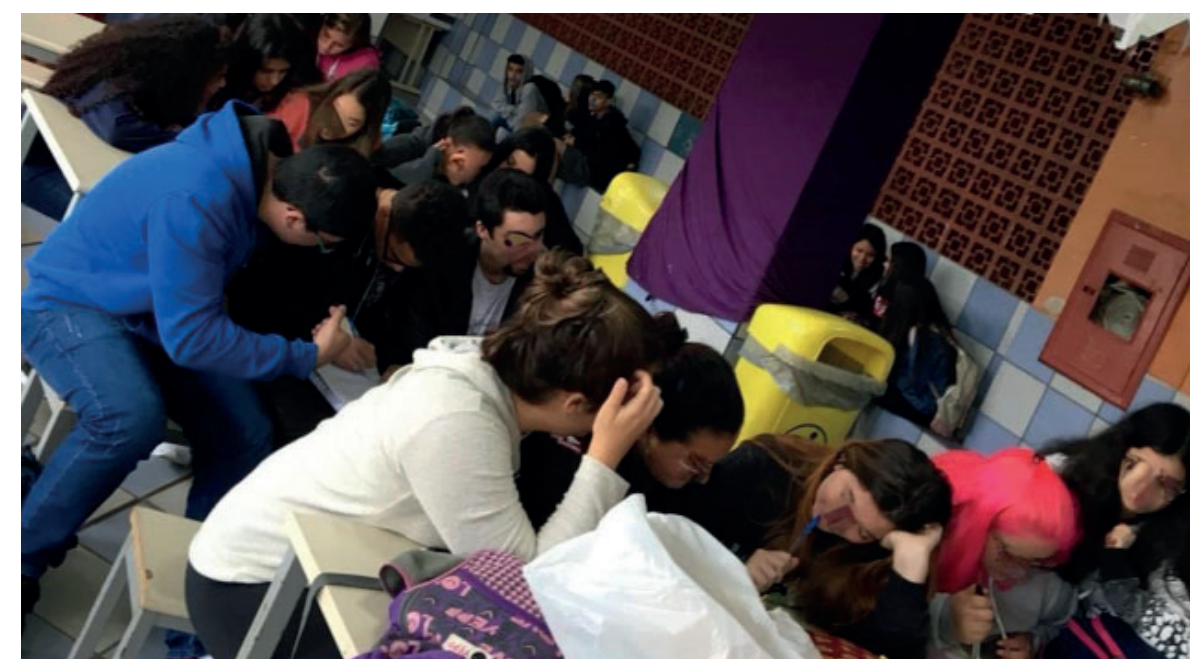

Figura 3: Dinâmica em grupo.

Fonte: Dados deste projeto.

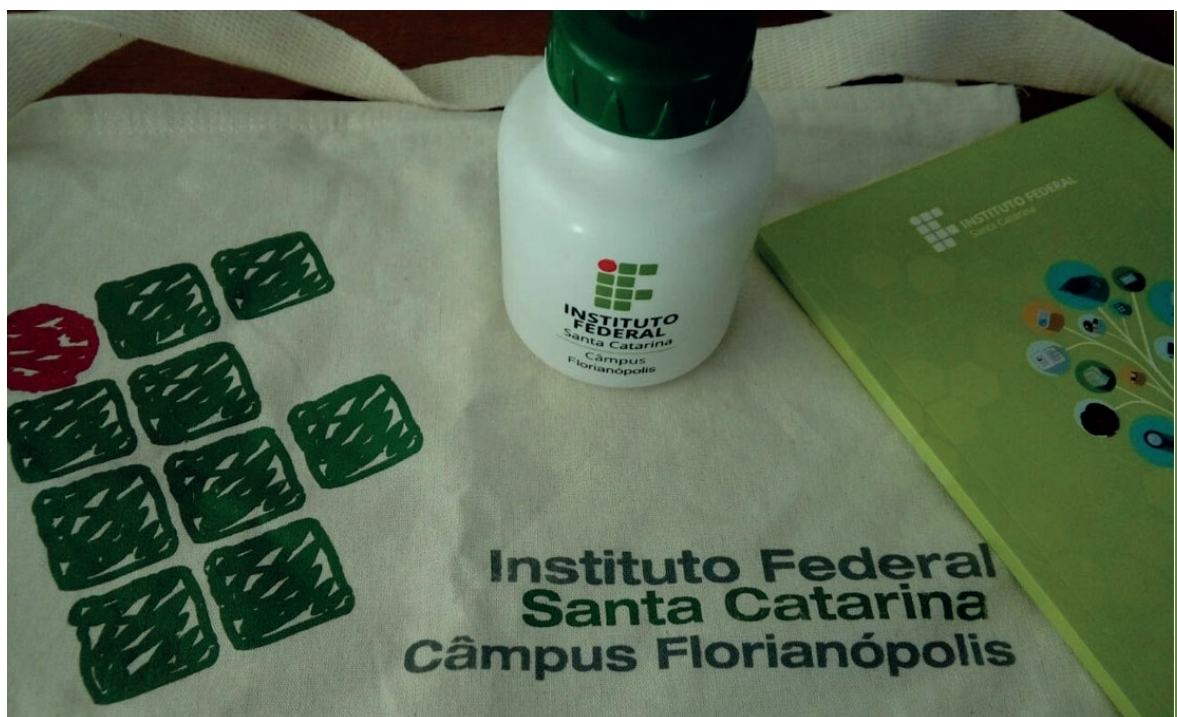

Figura 4: Brindes entregues aos alunos.

Fonte: Dados deste projeto.

A apresentação deu-se por encerrada no momento em que os graduandos se despediram e entregaram uma frase motivacional junto a um doce para cada aluno presente.

Baseado na experiência vivenciada percebeu-se que a universidade é um espaço que agrega diversos conhecimentos diferentes. Ela não apenas forma os alunos para uma carreira profissional como também estende seus limites de aprendizagem, criatividade e experiências, assim como os prepara para conviver com pessoas externas e aprender com elas.

Neste projeto de extensão os graduandos do Curso Superior de Tecnologia em Radiologia tiveram a oportunidade de compartilhar do seu conhecimento adquirido em sala de aula com alunos do ensino médio. Sendo que estes se encontram na fase de escolha acerca de qual graduação ou ensino técnico escolher e, ainda, por qual instituição optar. Neste aspecto percebeu-se que poucos participantes compreendiam a radiologia e como ela se aplica no mercado de trabalho, além do desconhecimento da existência do IFSC.

A extensão permitiu que os alunos da graduação aprofundassem seus conhecimentos nos conceitos explicados, além da troca de experiências que permitiu o enriquecimento profissional dos graduandos. Portanto, estas caraterísticas demonstram que a disciplina "Atividade de Extensão 1" atendeu às expectativas e alcançou os objetivos propostos de promover a interação entre estudantes e comunidade externa.

\section{Referências}

BIRAL, AR. Radiações ionizantes para médicos, físicos e leigos. 1 ed. Florianópolis:

Insular, 2002. 
FÓRUM DE PRÓ-REITORES DE EXTENSÃO DAS UNIVERSIDADES PÚBLICAS BRASILEIRAS - FORPROEX, 2010, Belo Horizonte. Extensão Universitária: organização e sistematização. Belo Horizonte: COOPMED, 2010.

IFSC, Câmpus Florianópolis. Disponível em: http://florianopolis.ifsc.edu.br/images/stories/ppc/ graduacao/_PPC_CST_RAD_vers\%C3\%A30_15.pdf. Acesso em:18 de abril de 2018.

MENEGON, Rodrigo. Lima, Márcia. Lima. José. Romero, Luiz. A Importância dos Projetos de Extensão no Processo de Formação Inicial de Professores de Educação Física. FCT/UNESP, PROEX. Presidente Prudente, 2015.

OKUNO, Emico. Efeitos biológicos das radiações ionizantes. Acidente radiológico de Goiânia. Estudos Avançados. 27 (77), 2013.

SARAIVA, J. L. Papel da Extensão Universitária na Formação de Estudantes e Professores. Brasília Médica, Brasília, v. 44, n. 3, p. 220-225, 2007. 